\title{
Control of vascular smooth muscle cell growth by connexin 43
}

\author{
Chintamani N. Joshi ${ }^{1}$, Danielle N. Martin ${ }^{1}$, Patti Shaver ${ }^{1}$, Chaitanya Madamanchi ${ }^{1}$, Barbara J. Muller-Borer ${ }^{2}$ \\ and David A. Tulis ${ }^{1}$ *
}

1 Department of Physiology, Brody School of Medicine, East Carolina University, Greenville, NC, USA

${ }^{2}$ Department of Cardiovascular Sciences, Brody School of Medicine, East Carolina University, Greenville, NC, USA

Edited by:

Timothy R. Nurkiewicz, West Virginia

University, USA

Reviewed by:

Timothy R. Nurkiewicz, West Virginia University, USA

Daniel Joseph Conklin, University of

Louisville, USA

*Correspondence:

David A. Tulis, Department of Physiology, Brody School of

Medicine, East Carolina University,

6E-108, 600 Moye Boulevard,

Greenville, NC 27834, USA.

e-mail: tulisd@ecu.edu
Connexin $43(\mathrm{C} \times 43)$, the principal gap junction protein in vascular smooth muscle cells (VSMCs), regulates movement of ions and other signaling molecules through gap junction intercellular communication (GJIC) and plays important roles in maintaining normal vessel function; however, many of the signaling mechanisms controlling Cx43 in VSMCs are not clearly described. The goal of this study was to investigate mechanisms of $\mathrm{C} \times 43$ regulation with respect to VSMC proliferation. Treatment of rat primary VSMCs with the CAMP analog 8Br-cAMP, the soluble guanylate cyclase (sGC) stimulator BAY 41-2272 (BAY), or the $\mathrm{Cx}$ inducer diallyl disulfide (DADS) significantly reduced proliferation after $72 \mathrm{~h}$ compared with vehicle controls. Bromodeoxyuridine uptake revealed reduction $(p<0.05)$ in DNA synthesis after $6 \mathrm{~h}$ and flow cytometry showed reduced (40\%) S-phase cell numbers after $16 \mathrm{~h}$ in DADS-treated cells compared with vehicle controls. Cx43 expression significantly increased after 270 min treatment with 8Br-cAMP, 8Br-cGMP, BAY or DADS. Inhibition of PKA, PKG or PKC reversed 8Br-cAMP-stimulated increases in Cx43 expression, whereas only PKG or PKC inhibition reversed 8Br-cGMP- and BAY-stimulated increases in total Cx43. Interestingly, stimulation of $\mathrm{C} \times 43$ expression by DADS was not dependent on PKA, PKG or PKC. Using fluorescence recovery after photobleaching, only 8Br-cAMP or DADS increased GJIC with 8Br-CAMP mediated by PKC and DADS mediated by PKG. Further, DADS significantly increased phosphorylation at MAPK-sensitive Serine (Ser)255 and Ser279, the cell cycle regulatory kinase-sensitive Ser262 and PKC-sensitive Ser368 after 30 min while 8BrcAMP significantly increased phosphorylation only at Ser279 compared with controls. This study demonstrates that 8Br-cAMP- and DADS-enhanced GJIC rather than Cx43 expression and/or phosphorylation plays important roles in the regulation of VSMC proliferation and provides new insights into the growth-regulatory capacities of Cx43 in VSM.

Keywords: vascular smooth muscle cells, Cx43, cAMP, cGMP, protein kinases

\section{INTRODUCTION}

Coordination of vascular cell responses is necessary for normal vessel function and is largely regulated by ionic intercellular coupling via gap junctions. Gap junctional intercellular communication (GJIC) uniquely allows the cellular exchange of metabolites, ions, and other small molecules such as second messengers which play important roles in transverse and longitudinal signaling in the vascular bed (Coutinho et al., 2003; Liao et al., 2007; Chadjichristos et al., 2008). Intercellular communication through gap junctions in cardiovascular tissues is involved in diverse processes such as determination of vasomotor tone, cell differentiation, growth control, embryonic development, and coordination of contraction of cardiac muscle cells (Yamasaki et al., 1996; Liao et al., 2007; Chadjichristos et al., 2008). Bidirectional cellular communication conducted by gap junctions is also believed to be integral in acetylcholine-induced vasoconstriction (Figueroa and Duling, 2009) and in maintaining cell quiescence (Zhang et al., 2003).

Gap junctions are comprised of connexin $(\mathrm{Cx})$ proteins (Kumar and Gilula, 1996; Yamasaki and Naus, 1996) and serve as transmembrane channels that act as intercellular conduits for GJIC. In the vasculature, gap junction channels are formed from combinations of one or more of the four connexin protein isomers: Cx37, 40, 43, and/or 45 (Little et al., 1995; Evans and Martin, 2002; Johnstone et al., 2009) and the predominant connexin in vascular smooth muscle (VSM) is Cx43 (Haefliger et al., 2004; Saitongdee et al., 2004; Isakson et al., 2006). Reduction in Cx43 protein expression and functionality have been associated with enhanced VSM cell (VSMC) proliferation and differentiation in atherosclerotic plaques (Kwak et al., 2002); however, the mechanisms for altered Cx43 expression in atherogenesis have not been well described but are thought to contribute to its disease progression. Studies have demonstrated that loss of Cx43 (Solan et al., 2003; Shao et al., 2005; Norris et al., 2008) or altered Cx phosphorylation status (Dang et al., 2006; Solan and Lampe, 2007) is sufficient to enhance the proliferative capacity of cells. Cx43 may undergo multiple phosphorylation events and at least five phosphorylated Serines (Ser) have been detected on $\mathrm{Cx} 43$ isolated from non-stimulated cells and several more have been identified under growth 
factor- or kinase-stimulated conditions (Lampe and Lau, 2004). These phosphorylation events correlate with changes in assembly and degradation of $\mathrm{Cx} 43$ gap junction channels and thus could play important roles in regulating GJIC (Cooper et al., 2000), yet their physiological significance particularly in VSM remains largely uncharacterized.

Cyclic AMP (cAMP) and cyclic GMP (cGMP) are ubiquitous second messengers that are involved in a variety of functions during vascular homeostasis and following injury or disease; however, the exact roles for cAMP and cGMP in the regulation of connexins and GJIC are not clear. It has been reported that activation of the nitric oxide (NO)/cGMP system induces $\mathrm{Cx} 43$ expression and increases GJIC (Yao et al., 2005), yet full characterization of cAMP and $\mathrm{CGMP}$ and their physiological influence on $\mathrm{Cx} 43$ expression and functionality in VSM is warranted.

The overall objective of the present study was to determine the relation between $\mathrm{Cx} 43$ expression, functionality, and phosphorylation states with respect to cell proliferation in VSMCs in the presence of cAMP and cGMP analogs and in comparison to the indirect soluble guanylate cyclase (sGC) stimulator BAY 41-2272 (BAY) and the Cx43 stimulant and garlic compound diallyl disulfide (DADS). In summary, results from this study show that an increase in Cx43-mediated GJIC is essential for control of proliferation in primary VSMCs and that enhanced expression and/or differential phosphorylation of $\mathrm{Cx} 43$ alone do not serve as effective growth regulators. Moreover, evidence is presented supporting roles for $8 \mathrm{Br}$-cAMPand DADS and physiologically effective agents in the control of VSM growth.

\section{MATERIALS AND METHODS ISOLATION AND CULTURE OF RAT PRIMARY VSMCs}

This study abided by the guidelines of the East Carolina University Animal Care and Use Committee and conformed to the Guide for the Care and Use of Laboratory Animals (US NIH, Pub. No. 85-23, rev. 1996). Male Sprague-Dawley rats $(100-125 \mathrm{~g})$ were anesthetized [ketamine $(90 \mathrm{mg} / \mathrm{ml})$, xylazine $(10 \mathrm{mg} / \mathrm{ml} ; 1 \mathrm{ml} / \mathrm{kg}$, i.p.)] and euthanized by pneumothorax and exsanguination. Vascular SMCs (VSMCs) were harvested from the thoracic aorta and isolated by collagenase and elastase digestion as described (Durante et al., 1993; Liu et al., 2009). Cells were cultured serially (passage 1-6) in Dulbecco's minimum essential media (DMEM) supplemented with 10\% fetal bovine serum (FBS), $2 \mathrm{mM}$ L-glutamine, sodium pyruvate, $5 \mathrm{mM}$ HEPES, and Primocin $(100 \mathrm{mg} / \mathrm{l})$ in the presence of $95 \%$ air $/ 5 \% \mathrm{CO}_{2}$.

\section{TREATMENTS}

Unless otherwise stated, VSMCs were treated with 8Br-cAMP or 8Br-cGMP (Adderley et al., 2012) at $100 \mu \mathrm{M}$, BAY 41-2272 at $100 \mathrm{nM}$, or DADS at $50 \mu \mathrm{M}$. For treatments involving kinase inhibition, VSMC were treated with PKI $(10 \mu \mathrm{M}$; Schlegel and Waschke, 2009) for inhibition of PKA, DT2 (YGRKKRRQRRRPPLRKKKKKH-amide; $10 \mu \mathrm{M}$; Dostmann et al., 2002; Dey et al., 2005) to inhibit PKG, or calphostin-C (CalC; $100 \mathrm{nM}$; Touyz and Schiffrin, 1997) to inhibit PKC for $15 \mathrm{~min}$ prior to treatment with vehicle, $8 \mathrm{Br}$-cAMP, $8 \mathrm{Br}$-cGMP, BAY, or DADS.

\section{MTT ASSAY}

Vascular smooth muscle cells were plated onto 96-well plates at 21,000 cells/well and treated with $8 \mathrm{Br}$-cAMP, 8Br-cGMP, BAY, or DADS. After 12 or $72 \mathrm{~h}$ 2,5-diphenyltetrazolium bromide (MTT) solution was added to the media and the cells incubated for $3 \mathrm{~h}$. The MTT-containing media was discarded and the cells were gently washed with PBS. Formazan formed within the cells was then dissolved in acetic-isopropanol and the plate was read at $570 \mathrm{~nm}$ with correction at $750 \mathrm{~nm}$. The optical density (OD) of the treatments was normalized to vehicle controls.

\section{HEMOCYTOMETRY AND NEUTRAL RED UPTAKE}

Hemocytometry was performed after $72 \mathrm{~h}$ to obtain viable cell numbers and Neutral Red Uptake was performed after $12 \mathrm{~h}$ as an estimate of cellular toxicity per established protocols (Mendelev et al., 2009; Joshi et al., 2011).

\section{BrdU UPTAKE}

The rate of DNA synthesis was measured with 5-bromo-2'deoxyuridine (BrdU) labeling (Giordano et al., 2008) with detection (Detection Kit II, Roche Diagnostics Corporation, Indianapolis, IN, USA) following manufacturer's instructions. Briefly, cells were plated onto 96-well plates at 21,000 cells/well. After quiescing overnight, cells were treated with $8 \mathrm{Br}$-cAMP, $8 \mathrm{Br}$-cGMP, BAY, or DADS for $2 \mathrm{~h}$ followed by BrdU treatment for $4 \mathrm{~h}$. Cells were fixed and incubated in the presence of the anti-BrdU antibody for $1 \mathrm{~h}$, after which the antibody was removed and the detection reagent added. The plate was read on a spectrophotometer at $370 \mathrm{~nm}$ with a reference at $492 \mathrm{~nm}$. The OD of the treatments was normalized to vehicle controls.

\section{CELL CYCLE ANALYSIS}

Flow cytometric cell cycle analysis was performed as described (Joshi et al., 2011). Briefly, VSMCs were seeded in 24-well plates (100,000 cells/well) and after adherence were quiesced overnight in DMEM containing $0.2 \%$ FBS. Cells were treated with vehicle, $8 \mathrm{Br}$-cAMP or DADS for $16 \mathrm{~h}$. The cells were trypsinized, fixed in cold ethanol, stained with propidium iodide, and subjected to flow cytometry (Accuri C6).

\section{IN-CELL WESTERN BLOTTING}

The effects of 8Br-cAMP, 8Br-cGMP, BAY, or DADS alone or in the presence of PKA, PKG, or PKC inhibitors PKI, DT2, or CalC on Cx43 expression in VSMCs were studied using the in-cell Western (ICW) method (Chen et al., 2005). Primary VSMCs were seeded in black 96-well flat bottom plates at 21,000 cells/well and following attachment were treated with respective agents for 30 or $270 \mathrm{~min}$ or $24 \mathrm{~h}$. For inhibitor studies, VSMCs were pretreated for 15 min with PKI $(10 \mu \mathrm{M})$, DT2 $(10 \mu \mathrm{M})$, or CalC $(100 \mathrm{nM})$ followed by treatment with $8 \mathrm{Br}$-cAMP, $8 \mathrm{Br}$-cGMP, BAY, or DADS for $270 \mathrm{~min}$. Reactions were stopped by replacing media with $4 \%$ phosphate-buffered formalin. Fixed cells were permeabilized with $0.1 \%$ Triton, blocked, and incubated with IR-tagged rabbit antibodies against $\mathrm{Cx} 43$ or the phosphorylated forms of $\mathrm{Cx} 43$ at Serines 255, 262, 279, and 368 (Cell Signaling) along with mouse $\alpha$-tubulin (Sigma) as the housekeeping control at 1:500 dilutions overnight at $4^{\circ} \mathrm{C}$. Cells were washed with PBS-Tween and incubated with anti-rabbit IR 800 and anti-mouse IR 680 (Rockland) 
secondary antibodies for $1 \mathrm{~h}$. The proteins were quantified by fluorescence (LiCor Odyssey) and normalized with respect to $\alpha$ tubulin within each well. All treatments were normalized to vehicle control.

\section{WESTERN BLOTTING}

Western blotting was performed on whole cell lysates as previously described (Mendelev et al., 2009) with slight modifications. After treatment with $8 \mathrm{Br}$-cAMP, $8 \mathrm{Br}$-cGMP, BAY, or DADS for $270 \mathrm{~min}$, cells were collected, homogenized, sonicated, boiled, and SDS-PAGE was performed using $20 \mu \mathrm{g}$ protein samples. The separated blots were transferred to nitrocellulose membrane, blocked, and incubated overnight at $4^{\circ} \mathrm{C}$ with IR-tagged antibodies against rabbit $\mathrm{Cx} 43$ protein (Millipore) and mouse $\alpha$-tubulin (Sigma) at 1:3000 dilutions. After washes the membranes were incubated in anti-rabbit IR800 and anti-mouse IR680 secondary antibodies (Rockland; 1:3000) for $1 \mathrm{~h}$ at room temperature. Blots were washed and proteins were quantified by fluorescence densitometry (Li-Cor Odyssey) and normalized with respect to $\alpha$-tubulin.

\section{GAP JUNCTION COMMUNICATION}

Gap junction-mediated cell-cell communication was measured using a fluorescence recovery after photobleaching (FRAP) assay as described (Goodwin and Kenworthy, 2005; Shen et al., 2010) with slight modifications. In this assay, recovery of fluorescence in a previously bleached cell is the result of influx of native dye from neighboring cells via gap junctions (Wade et al., 1986; MullerBorer et al., 2004; Shen et al., 2010). Thus, the FRAP assay is a direct measure of gap junction permeability and conductance and is a reliable measure of GJIC functionality. Moreover, FRAP is non-invasive, highly sensitive, and faster compared to more traditional GJIC approaches such as microinjection and dye transfer (Shen et al., 2010). Lastly, in this study FRAP measurements were performed after 15-min treatment, a physiologically relevant time point for the measurement of acute changes in gap junction function. Briefly, FRAP was performed using a laser scanning confocal microscope (Leica TCS-SP, Heidelberg, Germany), mounted on a Leica inverted microscope with a $63 \times$ water objective. Primary VSMCs were seeded ( $\sim 35,000$ cells) and grown to confluence on glass coverslips. For the loading of Calcein AM (Invitrogen), cells were washed with warm PBS and incubated in phenol-free DMEM containing Calcein AM $(1 \mu \mathrm{M})$ for $45 \mathrm{~min}$, washed with warm PBS and incubated in 10\% FBS in DMEM. Cells were treated for $15 \mathrm{~min}$ with either 8Br-cAMP, $8 \mathrm{Br}$-cGMP, BAY, or DADS and subjected to FRAP. In the inhibitor study with $8 \mathrm{Br}$-cAMP and DADS, $15 \mathrm{~min}$ treatment of the respective PKA, PKG, and PKC inhibitors PKI $(10 \mu \mathrm{M})$, DT2 $(10 \mu \mathrm{M})$, or CalC $(100 \mathrm{nM})$ was followed by treatment with $8 \mathrm{Br}$-cAMP or DADS. Individual cells connected with at least four cells on all the sides were selected for photobleaching. Calcein AM (Invitrogen Corp, Carlsbad, CA, USA) was excited by a high intensity argon laser pulse at $488 \mathrm{~nm}$ to bleach intracellular Calcein in selected cells and captured through grating at $530 / 30 \mathrm{~nm}$. The bleached cell was then monitored, and images were acquired continuously every $10 \mathrm{~s}$ for the initial minute, followed by 30 second intervals for 2 minutes and 1 minute intervals for another 2 minutes. GJIC between a cell and its neighbors was quantified by measuring the initial rate and percentage of fluorescence recovery. Non-photobleached cells were monitored as controls for spontaneous photobleaching. The rate of fluorescence recovery was estimated using the Zen (2009) software (Carl Zeiss) and the initial recovery rate constants were compared between the treated and vehicle controls. All treatments were normalized to vehicle control and expressed as percentage of vehicle controls.

\section{STATISTICAL ANALYSES}

Data were analyzed using Microsoft Excel 2007 and Sigma Plot 11 (SPSS, Inc.). Comparisons between treatment groups were made using one-way analysis of variance (ANOVA) and a multiple comparison Newman-Keuls post hoc test or Student's $t$-test as indicated. All data are presented as mean \pm SEM. A $p$-value of $<0.05$ is considered statistically significant for all comparisons.

\section{RESULTS}

\section{VSMC GROWTH}

Growth of VSMCs was assessed through use of the MTT assay and hemocytometric cell counts after $72 \mathrm{~h}$, flow cytometry after $16 \mathrm{~h}$, and BrdU incorporation after $6 \mathrm{~h}$. Mitochondrial dysfunction and cellular toxicity from all treatments were also evaluated after $12 \mathrm{~h}$. Using the MTT assay after $72 \mathrm{~h}, 8 \mathrm{Br}$-cAMP $(100 \mu \mathrm{M})$, BAY $(100 \mathrm{nM})$, or DADS $(50 \mu \mathrm{M})$ significantly reduced VSMC proliferation compared with vehicle controls; however, $8 \mathrm{Br}$-cGMP was without effect (Figure 1A). In agreement, hemocytometry after $72 \mathrm{~h}$ also revealed significant reduction in cell numbers following treatment with $8 \mathrm{Br}-\mathrm{cAMP}(100 \mu \mathrm{M})$ or BAY $(100 \mathrm{nM})$, and a nonsignificant trend ( $\sim 20 \%$ reduction; $p=0.06$ ) was observed for the DADS treatment group (Figure 1B). The MTT assay performed after $12 \mathrm{~h}$ indicated no observable mitochondrial dysfunction in any cohort (Figure 1C). Similarly, Neutral Red Uptake after $12 \mathrm{~h}$ showed no significant differences between treatment and vehicle control groups (data not shown).

Following BrdU uptake for $6 \mathrm{~h}$, DADS $(50 \mu \mathrm{M})$ significantly reduced $(20 \%)$ the rate of DNA synthesis compared with vehicle controls (Figure 2), yet $8 \mathrm{Br}$-cAMP, $8 \mathrm{Br}$-cGMP, or BAY showed no effects on DNA synthesis at this time point.

Flow cytometry performed as a measure of cell cycle progression showed that DADS significantly reduced the number of cells in the S-phase $(\sim 40 \%)$ compared with vehicle controls after $16 \mathrm{~h}$, while $8 \mathrm{Br}$-cAMP caused non-significant decreases in cell numbers in the $S$ and G2/M phases and a non-significant increase in G0/G1 cells (Figure 3).

\section{Cx43 EXPRESSION}

Using both IR-based Western and ICW analyses, incubation of rat primary VSMCs with $8 \mathrm{Br}$-cAMP or $8 \mathrm{Br}$-cGMP $(100 \mu \mathrm{M})$, BAY $(100 \mathrm{nM})$, or DADS $(50 \mu \mathrm{M})$ significantly increased total Cx43 expression (normalized to $\alpha$-tubulin) compared with vehicle controls after $270 \mathrm{~min}$ (Figure 4). Figure 4A shows densitometry results following ICW, and all agents increased total $\mathrm{Cx} 43$ by 20 $25 \%$. Interestingly, after $24 \mathrm{~h}$ only DADS significantly increased total $\mathrm{Cx} 43$ expression (Figure 4B). Of note, reducing the incubation period to $30 \mathrm{~min}$ in the presence of the four compounds showed no changes in $\mathrm{Cx} 43$ expression (data not shown). Using traditional, IR-Western blotting, the same trends were observed for increased total $\mathrm{Cx} 43$ expression (data not shown), yet the 


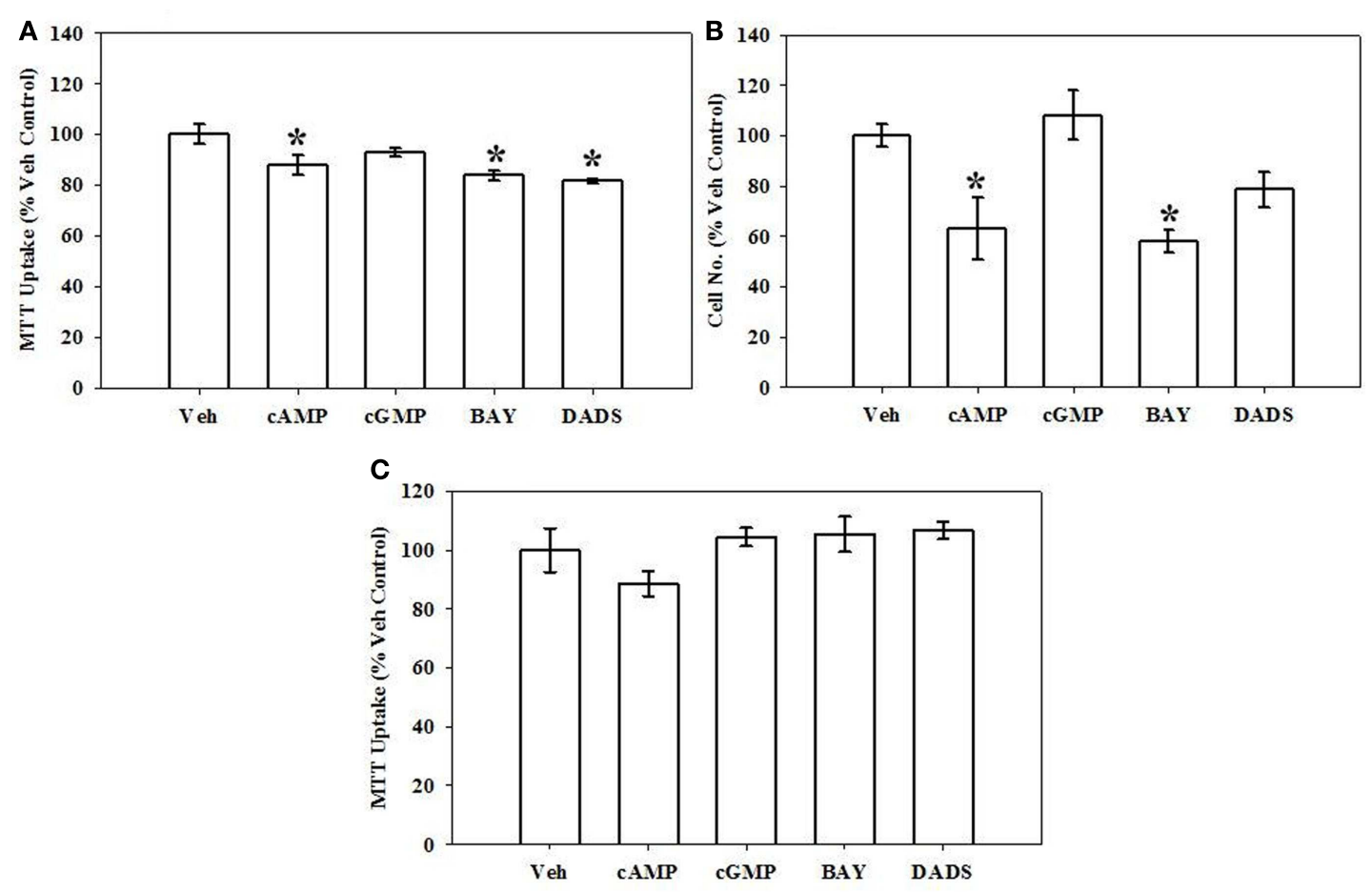

FIGURE 1 | Effects of cyclic nucleotide or Cx43 stimulation on VSMC proliferation. (A) In rat primary VSMCs in the presence of $10 \%$ serum for $72 \mathrm{~h}$ and using the MTT assay, 8Br-cAMP $(100 \mu \mathrm{M})$, the $\mathrm{sGC}$ stimulator BAY $(100 \mathrm{nM})$ or the garlic-derived CX inducer DADS $(50 \mu \mathrm{M})$ significantly reduced rat primary VSMC numbers compared with vehicle controls. Data are mean \pm SEM with an $n=6$. (B) Using hemocytometry after $72 \mathrm{~h}$, both $8 \mathrm{Br}-\mathrm{CAMP}$ and BAY significantly reduced cell numbers by $\sim 40 \%$, and the presence of DADS reduced cell numbers by $\sim 20 \%(p=0.06)$. Data are mean \pm SEM of two independent experiments each with $n=3-4$. (C) MTT assay performed on VSMCs after $12 \mathrm{~h}$ shows no observable changes in any treatment group. Student-Newman-Keuls method for multiple comparisons following one-way ANOVA was used. ${ }^{*} p<0.05$ compared with normalized vehicle controls.

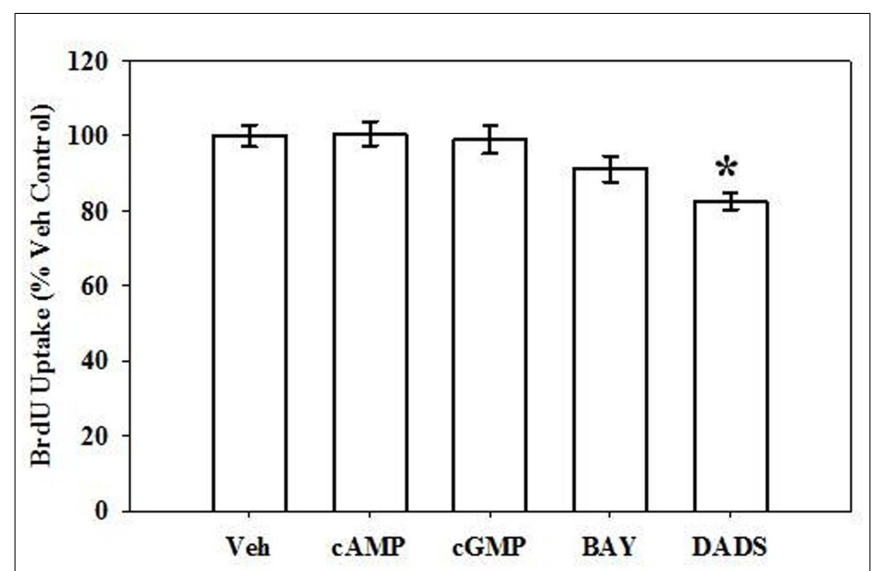

FIGURE 2 | Effects of cyclic nucleotide or Cx43 stimulation on VSMC DNA synthesis. In rat primary VSMCs in the presence of $10 \%$ serum for $6 \mathrm{~h}, \mathrm{DADS}(50 \mu \mathrm{M})$ significantly reduced the rate of DNA synthesis by $20 \%$ compared with vehicle controls estimated by BrdU incorporation. Data are mean \pm SE from three independent experiments each with an $n=6$. Student-Newman-Keuls method for multiple comparisons following one-way ANOVA was used. ${ }^{*} p<0.05$ compared with normalized vehicle controls. extent of increases was much higher than that observed with ICW. A representative IR-Western blot for total $\mathrm{Cx} 43$ expression is shown in Figure 4C. Figure 4D shows a representative photomicrograph of confluent VSMCs following immunocytochemical staining for $\mathrm{Cx} 43$ which shows punctate presence of gap junctions predominantly at cell-to-cell contacts (indicated by arrows).

\section{EFFECTS OF KINASE INHIBITION ON STIMULATED CX43 EXPRESSION}

Kinase regulation of $\mathrm{Cx} 43$ expression in the presence of $8 \mathrm{Br}$-cAMP, 8Br-cGMP, BAY, or DADS was tested using selective kinase blockade and evaluated through ICW analysis. Respective inhibition of PKA, PKG, and PKC by PKI, DT-2, and CalC significantly reversed the stimulatory effects of $8 \mathrm{Br}$-cAMP on total $\mathrm{Cx} 43$ expression (Figure 5A). In comparison, only the inhibition of PKG and PKC (by DT-2 and CalC, respectively) reversed the stimulation of $\mathrm{Cx} 43$ expression induced by both the direct-activating 8Br-cGMP (Figure 5B) and the indirect sGC stimulator BAY (Figure 5C). Inhibition of any of the kinases, PKA, PKG, or PKC, did not have any effect on DADS-induced stimulation of Cx43 expression (Figure 5D). Lastly, each inhibitor alone failed to alter basal (vehicle-treated) total Cx43 expression (Figure 5E). A summary of results from the kinase inhibitor studies on $\mathrm{Cx} 43$ expression is shown in Table 1. 


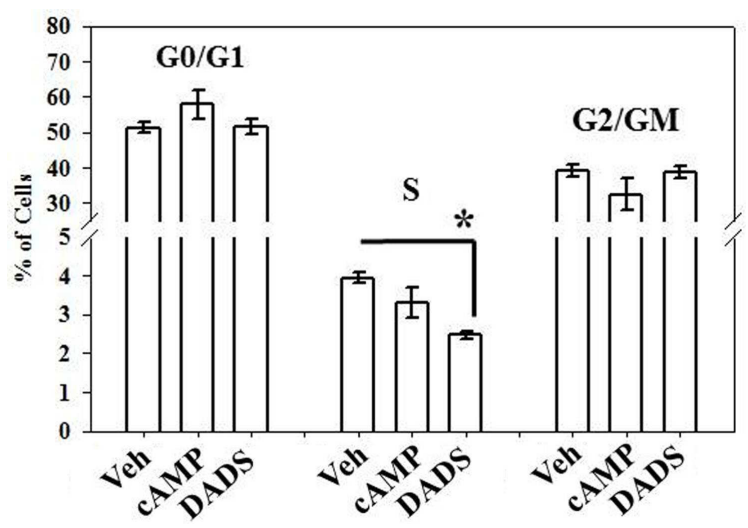

FIGURE 3 | Effects of 8Br-cAMP and DADS on $10 \%$ FBS-stimulated VSMC cell cycle progression. Using flow cytometry after $16 \mathrm{~h}$ incubation, a $40 \%$ reduction in the percentage of cells in the S-phase was observed in the presence of DADS $(50 \mu \mathrm{M})$ with no significant changes in the $\mathrm{G} 0 / \mathrm{G} 1$ or $\mathrm{G} 2 / \mathrm{M}$ phases compared with vehicle controls. Data are mean $\pm \mathrm{SEM}$ with an $n=3$. Student-Newman-Keuls method for multiple comparisons following one-way ANOVA was used. * $p<0.05$ compared with vehicle controls.

\section{CELL-TO-CELL COMMUNICATION}

Using FRAP as a measure of GJIC and gap junction functionality, incubating cells for $15 \mathrm{~min}$ in the presence of $8 \mathrm{Br}$-cAMP increased GJIC by $50 \%$ and in the presence of DADS by $80 \%$ over vehicle controls while the presence of $8 \mathrm{Br}-\mathrm{cGMP}$ or BAY had no effect (Figure 6A). After 270 min 8 Br-cAMP or DADS failed to enhance GJIC (data not shown). Representative photomicrographs of adherent VSMCs subjected to FRAP analysis are shown (Figures 6B-E) with the photobleached cell of interest outlined. Figure 6B shows a cell immediately prior to photobleaching; Figure 6C shows that cell immediately after photobleaching; Figure 6D shows the cell $2.5 \mathrm{~min}$ after photobleaching and some degree of fluorescent recovery is apparent; Figure $6 \mathrm{E}$ shows the cell $4.5 \mathrm{~min}$ after photobleaching at the conclusion of fluorescence recovery.

To examine kinase involvement in the acute stimulation of GJIC by $8 \mathrm{Br}$-cAMP or DADS, FRAP was studied following select kinase inhibition in the presence of $8 \mathrm{Br}$-cAMP or DADS. GJIC stimulated by $8 \mathrm{Br}$-cAMP was reversed by $\mathrm{PKC}$ inhibition alone (Figure 7A), whereas GJIC stimulated by DADS was markedly subdued $(p=0.06)$ by DT-2-mediated inhibition of PKG alone (Figure 7B).

\section{CX43 PHOSPHORYLATION}

Site-specific phosphorylation of $\mathrm{Cx} 43$ was studied at four sites known to be sensitive to kinase activation: Ser255 and Ser279 (MAPK-specific), Ser262 (p34 ${ }^{\text {cdc2 }}$ kinase-specific), and Ser368 (PKC-specific). In the presence of 8Br-cAMP, phosphorylation of Cx43 increased ( 20-30\%) at both MAPK-sensitive sites (Ser255 and Ser279) compared with vehicle controls, reaching statistical significance at the Ser279 site (Figure 8A). In comparison, DADS significantly increased ( $\sim 30 \%$ ) phosphorylation at MAPKsensitive Ser255 and Ser279, the p34 ${ }^{\mathrm{cdc} 2}$-sensitive Ser262, and the PKC-sensitive Ser368 (Figure 8B).

\section{DISCUSSION}

Accumulating evidence indicates a regulatory role for connexins and gap junction communication in a variety of vascular pathologies including hypertension (Figueroa et al., 2006; Brisset et al., 2009) ischemia/reperfusion injury (Jara et al., 1995), atherosclerosis (Blackburn et al., 1995; Polacek et al., 1997; Yeh et al., 1997), and the growth response to vascular injury (Yeh et al., 1997; Kurjiaka et al., 1998; Brisset et al., 2009). Mechanistically, a variety of controlling elements have been examined for $\mathrm{Cx}$ (Figueroa and Duling, 2009), yet few reports have investigated a role for cyclic nucleotides in the control of $\mathrm{Cx} 43$ expression and functionality with respect to VSM growth. Hence, this study aimed to understand the physiological relevance of $\mathrm{Cx} 43$ regulation by cyclic nucleotide signaling in VSM growth. Using rat primary VSMCs, the cyclic nucleotide analog 8Br-cAMP and the garlic-derived diallyl compound DADS reduced proliferation and DNA synthesis and increased $\mathrm{Cx} 43$ expression and functionality, establishing a direct link between VSMC proliferation and $\mathrm{Cx} 43$. It was also observed that distinct protein kinase signals have capacity to regulate $\mathrm{Cx} 43$ expression and functionality that are modulated by $8 \mathrm{Br}$-cAMP and DADS. In summary, this study provides direct evidence for the mechanistic basis of gap junctional communication in the regulation of VSMC proliferation.

In this study both metabolically stable, direct-activating cyclic nucleotide analogs and indirect sGC stimulation were used to induce cyclic nucleotide signaling. Using 8Br-cAMP and $8 \mathrm{Br}-$ cGMP, after a 72-h exposure only 8Br-cAMP significantly reduced cell proliferation estimated by the MTT and hemocytometry assays, confirming an earlier report using a different cAMP ana$\log$ (Indolfi et al., 2000). In the current study it was interesting to note that $8 \mathrm{Br}$-cGMP failed to exert noticeable effects on VSMC growth as earlier studies report anti-proliferative effects by stimulation of cGMP-related pathways (Lincoln et al., 2006) but not by cGMP per se. To complement findings from the proliferation assays, two additional approaches were employed to examine VSMC growth. Bromodeoxyuridine uptake allows study of DNA synthesis whereas flow cytometry explores cell cycle progression. Most reports studying the effects of cGMP on VSMC proliferation involve indirect cGMP stimulation that may have untoward effects such as those mediated by cAMP considering that cGMPmediated inhibition of PDE3 increases cAMP levels (Maurice and Haslam, 1990). Remarkably, neither 8Br-cAMP nor 8Br-cGMP showed influence on the rate of DNA synthesis estimated by BrdU uptake after $6 \mathrm{~h}$. Nonetheless, using flow cytometry 8Br-cAMP showed insignificant decreases in S-phase and G2/M phase cells with a slight increase in G0/G1 cells after $16 \mathrm{~h}$. The effects on the nuclear mechanisms in the presence of $8 \mathrm{Br}$-cAMP were not evident at the acute time points analyzed; nonetheless, the inhibition of VSMC growth after $72 \mathrm{~h}$ was significant confirming earlier reports that elevated cAMP inhibits VSMC proliferation in vitro (Wu et al., 2006).

Recent findings from our lab provide solid evidence that pharmacologic sGC stimulation increases both cAMP and cGMP (Adderley et al., 2012) and inhibits neointimal growth after balloon injury (Joshi et al., 2011). In the current study in comparison to the effects of the cyclic nucleotide analogs, the sGC stimulator BAY 41-2272 (BAY) did not significantly reduce DNA synthesis but 

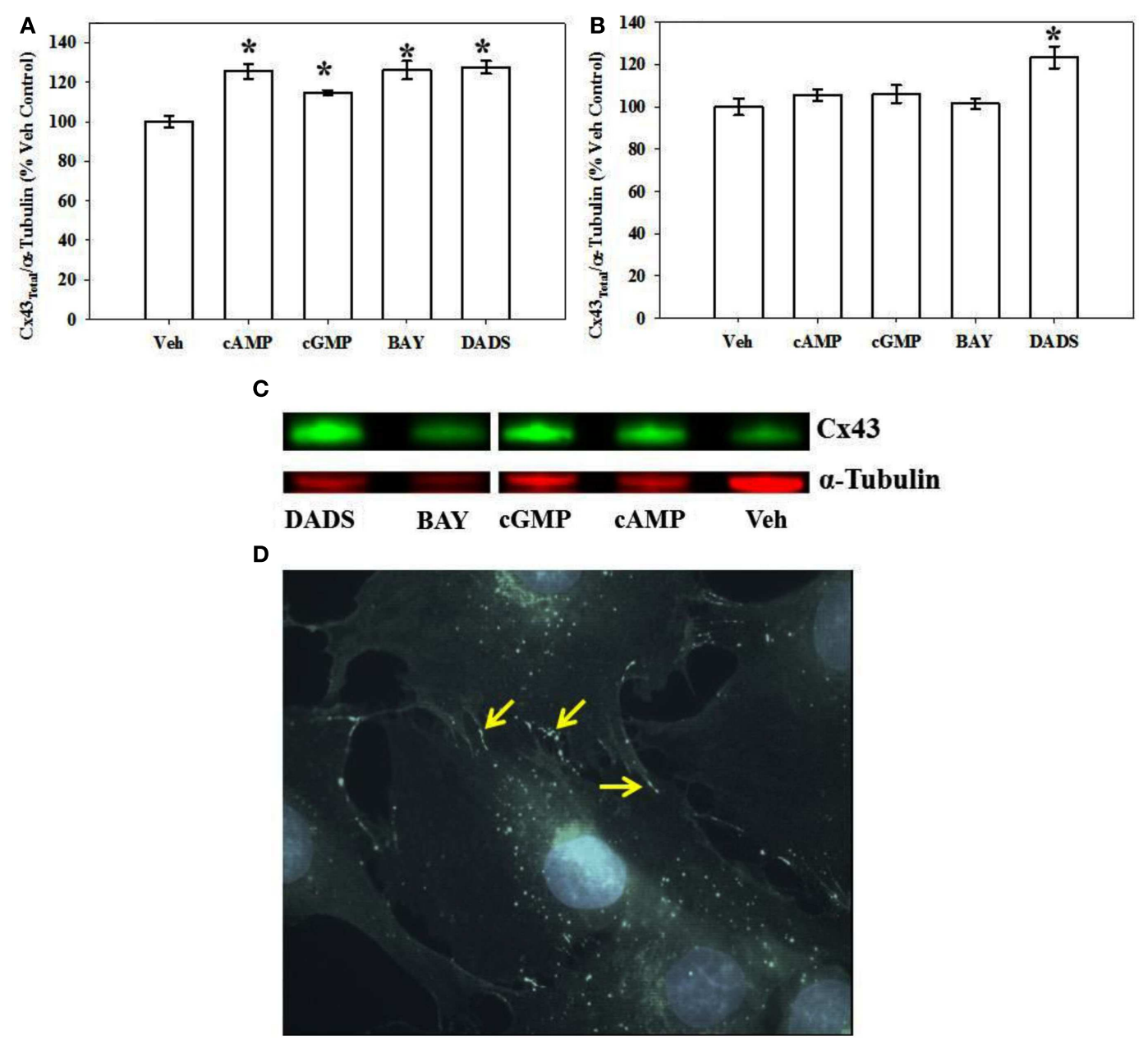

FIGURE 4 | Total Cx43 expression in VSMCs. (A) In-cell Western blotting for total Cx43 expression in rat primary VSMC homogenates. Incubation of rat primary VSMCs for $270 \mathrm{~min}$ in the presence of $8 \mathrm{Br}-\mathrm{cAMP}(100 \mu \mathrm{M})$, 8Br-cGMP $(100 \mu \mathrm{M}), \mathrm{BAY}(100 \mathrm{nM})$, or DADS $(50 \mu \mathrm{M})$ significantly stimulated total $\mathrm{C} \times 43$ expression normalized to $\alpha$-tubulin. Data are from two independent experiments each performed in triplicate. (B) After 24-h incubation the stimulation of $\mathrm{C} \times 43$ was significantly increased only after DADS treatment with no observable changes for the 8Br-cAMP, 8Br-cGMP, or BAY treatment groups compared with vehicle controls. For these experiments $n=6$ for each treatment. Student-Newman-Keuls method for multiple comparisons following one-way ANOVA was used. * $p<0.05$ compared with normalized vehicle controls. (C) A representative Western blot showing total Cx43 in green and $\alpha$-tubulin in red using IR-labeled antibodies. These data were obtained from a single Western blot with a column (unrelated to the current study) removed for clarity. (D) Photomicrograph of confluent VSMCs following immunocytochemical staining for total $\mathrm{C} \times 43$. Punctate appearance of $\mathrm{C} \times 43$ indicating the presence of gap junctions is predominantly at cell-to-cell contacts (indicated by arrows). reduced VSMC proliferation after $72 \mathrm{~h}$ as reported earlier (Joshi et al., 2011). This anti-proliferative effect of BAY was recently suggested to occur through Cdk suppression and elevation of p21 and p27 (Mendelev et al., 2009); however, that study used BAY at $10 \mu \mathrm{M}$ in commercial A7R5 VSMCs whereas the present study used BAY at $100 \mathrm{nM}$ in primary VSMCs. Additionally, this current study and our recent report (Joshi et al., 2011) attribute decreases in VSMC proliferation induced by BAY to changes in phosphorylation of vasodilator-activated serum phosphoprotein (VASP), a marker of differential kinase activation (Butt et al., 1994), and a critical cytoskeletal and focal adhesion element (Reinhard et al., 2001).

In the current study a significant reduction in VSMC growth and DNA synthesis by DADS was complemented by a decrease in the number of cells in the S-phase, estimated by flow cytometry. The inhibitory effects of DADS on cell growth in other systems have been mostly attributed to an increase in the apoptotic cell populations correlated with depressed $\mathrm{p} 34^{\mathrm{cdc} 2}$ kinase activity (Knowles and Milner, 2000), and at the same time DADS has been reported to be a potent stimulator of $\mathrm{Cx} 43$ expression and activity (Huard et al., 2004). DADS has been reported to induce S-phase block in tumorigenic CNE2 cells (Zhang et al., 2006), observed in the present study in VSMCs as well.

Expression of $\mathrm{Cx} 43$ has been reported to be regulated by cAMP in thymic epithelial cells (Nihei et al., 2010), but scientific evidence is lacking for the effects of cAMP or cGMP on Cx43 expression and functionality in primary VSM. The present study exclusively used primary VSMCs to study the effects of the 

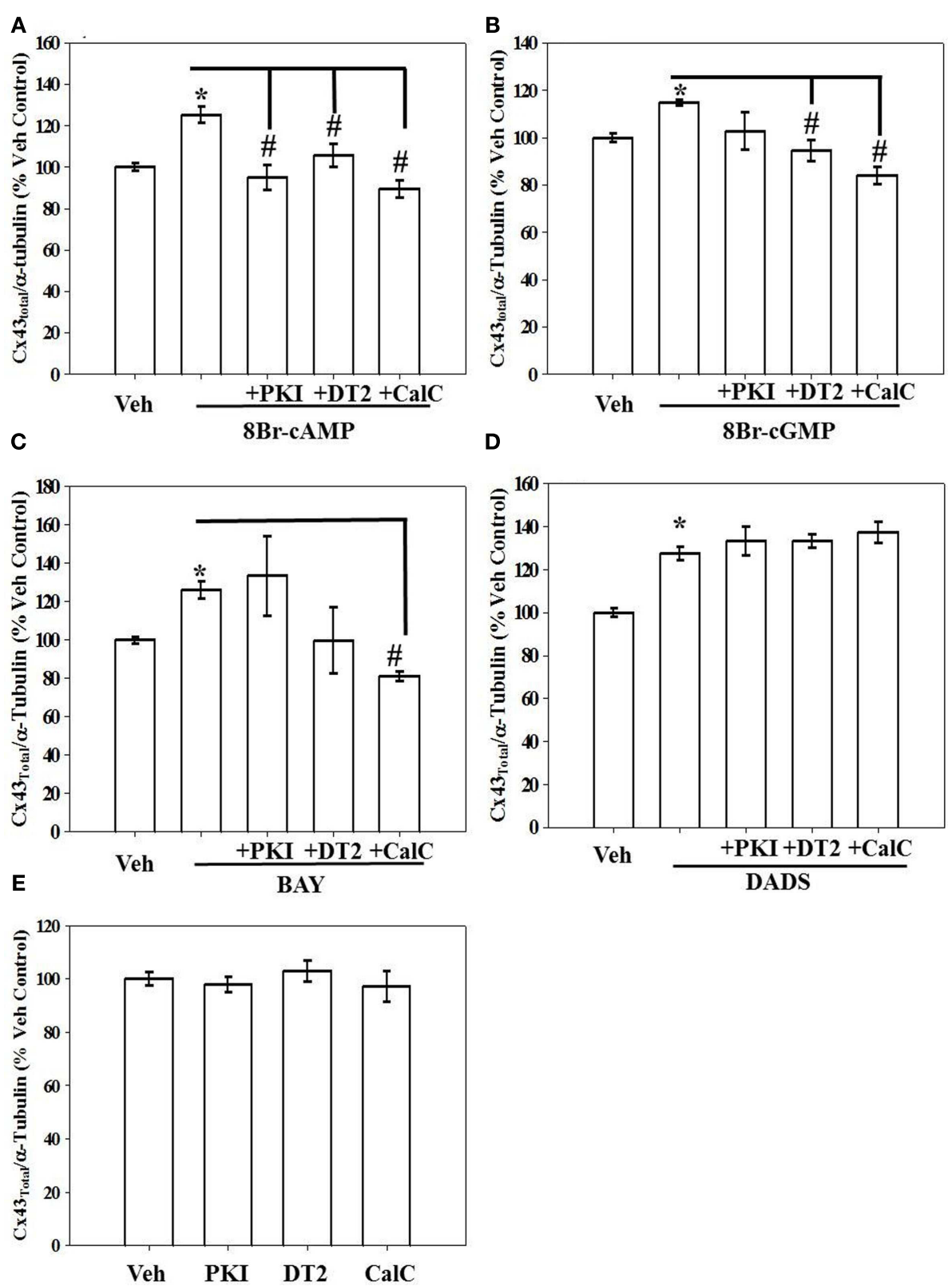

FIGURE 5 | Results from in-cell Western analyses showing effects of kinase inhibition on total Cx43 expression in rat primary VSMCs following incubation in the presence of (A) 8Br-cAMP $(100 \mu \mathrm{M})$, (B) 8Br-cGMP $(100 \mu \mathrm{M})$, (C) BAY (100 nM), and (D) DADS $(50 \mu \mathrm{M})$ for $270 \mathrm{~min}$. (A) Inhibition of PKA (by PKI), PKG (by DT2), or PKC (by CalC) each independently subdued 8Br-cAMP-induced increase in $\mathrm{C} \times 43$ expression. (B,C) Only PKG and PKC inhibition reversed the effects of $8 \mathrm{Br}-\mathrm{cGMP}$ and BAY,

brominated cyclic nucleotide analogs and BAY on Cx43 expression/functionality and to investigate the roles of PKA, PKG, and PKC in mediating these events. Both 8Br-cAMP and 8Br-cGMP stimulated total $\mathrm{Cx} 43$ protein expression providing direct evidence for the regulation of $\mathrm{Cx} 43$ by cyclic nucleotides in VSMCs. These cyclic nucleotide analogs are known to act via kinase pathways. The known inhibitors PKI, DT-2, and CalC were used for respectively. (D) Stimulation of $\mathrm{C} \times 43$ expression in the presence of DADS was not dependent on PKA, PKG, or PKC. (E) Treatment with any individual kinase inhibitor did not affect total basal $\mathrm{C} \times 43$ expression compared with vehicle controls. Data are mean \pm SE from $n=4-7$ for each treatment.

Student-Newman-Keuls method for multiple comparisons following one-way ANOVA was used. ${ }^{*} p<0.05$ compared with normalized vehicle controls;

$\# p<0.05$ comparing inhibitors to agonists alone normalized to vehicle controls. respective inhibition of PKA, PKG, and PKC, and inhibition of all the three individual kinases reversed 8Br-cAMP-stimulated Cx43 expression, providing direct evidence for the role of all the three kinases in 8Br-cAMP-mediated stimulation of $\mathrm{Cx} 43$ expression. At the same time an involvement of only the PKG and PKC pathways was evident in $8 \mathrm{Br}$-cGMP stimulation of $\mathrm{Cx} 43$ expression as only DT-2 and CalC reversed $8 \mathrm{Br}$-cGMP-mediated stimulation 
Table 1 | Table showing the summary of the effect of 8Br-cAMP, 8Br-cGMP, BAY, and DADS on Cx43 expression and the regulation of this Cx43 stimulation by the respective kinases.

\begin{tabular}{lllll}
\hline & & \multicolumn{3}{c}{ Kinase inhibitors } \\
\cline { 3 - 5 } Treatment & Total & w/PKI & w/DT-2 & w/CaIC \\
& Cx43 & (PKA & (PKG & (PKC \\
& expression & inhibition) & inhibition) & inhibition) \\
\hline 8Br-CAMP & $\uparrow$ & $\downarrow$ & $\downarrow$ & $\downarrow$ \\
8Br-cGMP & $\uparrow$ & - & $\downarrow$ & $\downarrow$ \\
BAY 41-2272 & $\uparrow$ & - & $\downarrow$ & $\downarrow$ \\
DADS & $\uparrow$ & - & - & - \\
\hline
\end{tabular}

of $\mathrm{Cx} 43$ expression. This is the first report providing evidence for involvement of cyclic nucleotide-mediated kinase pathways in the regulation of $\mathrm{Cx} 43$ expression in primary VSM. In comparison to these direct analogs, the sGC/cGMP stimulator BAY was also observed to stimulate $\mathrm{Cx} 43$ expression that was reversed by the inhibition of PKG and PKC, the same kinases that were involved in the stimulation of $\mathrm{Cx} 43$ expression by $8 \mathrm{Br}$-cGMP. The diallyl compound DADS is known to stimulate Cx43 in rat liver cells (Huard et al., 2004), and in the current study was found to increase Cx43 expression and conductance in rat primary VSMCs. Interestingly, these effects of DADS on Cx43 expression appear independent of the kinase pathways studied here, namely PKA, PKG, or PKC.

Although 8Br-cAMP, 8Br-cGMP, BAY, and DADS each independently increased $\mathrm{Cx} 43$ expression, it was only with $8 \mathrm{Br}$-cAMP and DADS that an increase in GJIC was observed confirming earlier reports (Huard et al., 2004; Nihei et al., 2010). Although 8Br-cGMP has been observed to increase GJIC in other tissues such as the mesangium (Yao et al., 2005), similar effects on GJIC were not observed in the rat primary VSMC in this study. It is important to note that the increased GJIC reported earlier (Yao et al., 2005) in the presence of $8 \mathrm{Br}-\mathrm{cGMP}$ was in the presence of a very high concentration of analog $(500 \mu \mathrm{M})$ and observed after a 24-h incubation, whereas in the present study 8Br-cGMP was used at $100 \mu \mathrm{M}$ for 15 min under more physiologically realistic conditions. A high turnover rate $\left(t_{1 / 2} 1.5-3.5 \mathrm{~h}\right.$; Laird et al., 1991) has been observed for plasma membrane-localized Cx43. $\mathrm{Cx} 43$ also possesses multiple phosphorylation sites (Lampe and Lau, 2000). Thus, the purpose of using a shorter time point was to avoid potential changes in $\mathrm{Cx} 43$ expression levels and to investigate if rapid phosphorylation of $\mathrm{Cx} 43$ coincided with changes in GJIC. Furthermore, short-term incubation $(30 \mathrm{~min})$ in the presence of 8Br-cAMP, 8Br-cGMP, BAY, or DADS had no effects on the $\mathrm{Cx} 43$ expression levels (data not shown). A number of reports have shown that increased cAMP increases $\mathrm{Cx} 43$ expression, functionality, and phosphorylation (Lampe and Lau, 2004) and specifically the increase in Cx43 expression appears to be mediated by PKA (Paulson et al., 2000) in hepatoma cells and it has only recently been reported that the cAMP/PKA pathway regulates GJIC in mouse embryonic stem cells (Yun et al., 2012). The stimulation of GJIC by 8Br-cAMP observed in this study was reversed by the $\mathrm{PKC}$ inhibitor $\mathrm{CalC}$, and it was surprising to note that neither PKA nor PKG had any role in regulating 8Br-cAMP-stimulated GJIC. In rat primary VSMC crosstalk between the different kinases has been reported (Adderley et al., 2012; Joshi et al., 2011). Moreover, the different kinases may play varying roles in regulating $\mathrm{Cx} 43$ expression/functionality depending on their tissue/organ specificity and perhaps precise localization within the cellular milieu (Adderley et al., 2012).

In this effort the sGC modulator BAY did not exert noticeable effects on GJIC in rat primary VSMC. This is the first report studying the influence of BAY on $\mathrm{Cx} 43$ expression and functionality, and although BAY has been reported to inhibit VSMC proliferation through cGMP-dependent pathways (Mendelev et al., 2009) it does not seem to be dependent upon a functional $\mathrm{Cx} 43$. It could be possible, however, that the BAY-stimulated increase in $\mathrm{Cx} 43$ expression may have delayed effects on VSMC proliferation that were not evident at the time points observed in this study.

The diallyl garlic compound DADS has been reported to be cancer chomopreventive in a number of studies (Schaffer et al., 1996; Knowles and Milner, 2000; Arunkumar et al., 2006) and an important characteristic of DADS is its ability to stimulate Cx43 expression and GJIC (Huard et al., 2004). There is increasing evidence that GJIC alteration is involved in tumor cell development (Trosko and Ruch, 1998), and most studies using DADS have been performed on phenotypically modified or tumorigenic cells. This is the first report characterizing the effects of DADS on VSMC Cx43 with respect to proliferation, and data reveal that DADS stimulates acute GJIC. The shorter treatment time used in this study $(15 \mathrm{~min})$ is important as no changes in Cx43 protein expression were detected even after 30-min exposure, and thus these findings signify direct, translation-independent activation of Cx43 leading to the opening of gap junction channels and promoting GJIC. The inhibition of PKG by DT-2 reversed DADS-promoted GJIC in the rat primary VSMCs which was not reversed by either PKA or PKC inhibition. This observation indicates involvement of the PKG pathway in DADS stimulation, and in comparison with the role for PKC in the activation of GJIC by $8 \mathrm{Br}$-cAMP, clearly supports the notion of crosstalk between the kinases that appears to be tissue- and function-specific. The study also highlights the fact that the functionality of gap junctions plays a more important role in regulating the proliferation of VSMC than does simple expression of the gap junction proteins.

Considering the potential involvement of site-specific $\mathrm{Cx} 43$ phosphorylation in regulating GJIC that may control cell proliferation, phosphorylation of $\mathrm{Cx} 43$ was studied at the MAPK-sensitive sites Ser 255 and Ser279, the cell cycle regulatory $\mathrm{p} 34^{\text {cdc2 }}$-sensitive Ser262, and PKC-sensitive Ser368. Although both 8Br-cAMP and DADS had similar effects on VSMC growth and Cx43 expression and functionality, they have different site-specific $\mathrm{Cx} 43$ phosphorylation profiles. Using the ICW technique that is preferred for evaluation of phosphorylated residues, $8 \mathrm{Br}$-cAMP stimulated Cx43 phosphorylation at only the MAPK-sensitive Ser255 and Ser279 sites while DADS stimulated phosphorylation of Cx43 at multiple sites including Ser255 and Ser279, Ser262 and Ser368. Studies have demonstrated alteration in the proliferative state of a cell with a loss of Cx43 (Solan et al., 2003; Shao et al., 2005; Norris et al., 2008) or its altered phosphorylation status (Dang et al., 2006; Solan and Lampe, 2007). Changes in Cx43 phosphorylation and 

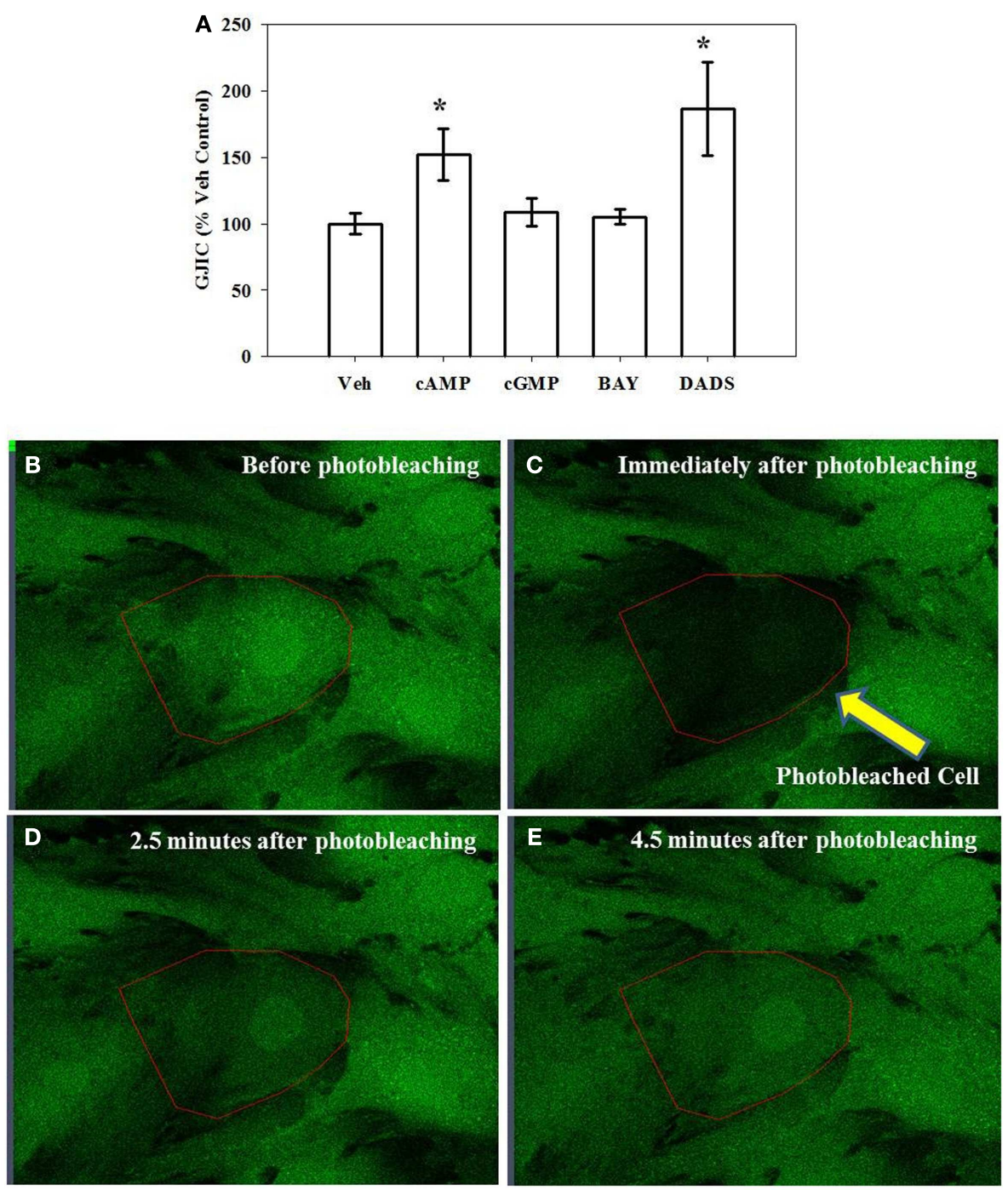

FIGURE 6 | Gap junction intercellular communication (GJIC) as an indicator of functionality estimated by fluorescence recovery after photobleaching (FRAP). (A) Incubation of rat primary VSMCs for $15 \mathrm{~min}$ in the presence of $8 \mathrm{Br}-\mathrm{CAMP}(100 \mu \mathrm{M})$ or DADS $(50 \mu \mathrm{M})$ significantly increased GJIC. Data are mean \pm SE from an $n=5-9$ for each treatment. Student-Newman-Keuls method for multiple comparisons following

gap junctional communication have also been observed as cells proceed through the cell cycle (Koo et al., 1997; Xie et al., 1997; Kanemitsu et al., 1998; Lampe et al., 1998; Bittman and LoTurco, 1999; Solan et al., 2003), indicating that GJIC and Cx43 phosphorylation are tightly regulated and linked during cell cycle. It is important to note that the role of $\mathrm{Cx} 43$ phosphorylation may differ considerably among cell types, stages of cell cycle, growth factor milieu and extracellular matrix interactions, and given its short $t_{1 / 2}$ and rapid turnover, its phosphorylative capacity must be closely regulated. Although a loss of GJIC has been reported in WB-F344 rat liver epithelial cells (Ruch et al., 2001) and in the IAR6.1 rat liver epithelial cell (Rivedal and Opsahl, 2001) line after TPA treatment along with $\mathrm{Cx} 43$ phosphorylation at the MAPK active sites, Ser255 one-way ANOVA was used. * $p<0.05$ compared with normalized vehicle controls. (B-E) Representative photomicrographs $(630 \times)$ of confluent VSMCs undergoing FRAP with the targeted cell outlined. (B) Before photobleaching; (C) immediately after photobleaching; (D) $2.5 \mathrm{~min}$ after photobleaching; and (E) $4.5 \mathrm{~min}$ after photobleaching at the conclusion of fluorescence recovery.

and Ser279, a similar effect was not seen in the rat primary VSMC after $8 \mathrm{Br}$-cAMP and DADS. In fact, increased phosphorylation of $\mathrm{Cx} 43$ at Ser255 and Ser279, MAPK-sensitive sites, correlated with reduced VSMC growth and improved GJIC. Ser262 is a p34 ${ }^{\mathrm{cdc} 2}$-sensitive phosphorylation site that has been reported to be involved in cell division (Laird, 2005). Following phosphorylation of $\mathrm{Cx} 43$ at Ser262 by $\mathrm{p} 34^{\mathrm{cdc} 2}$ protein kinase, a loss of gap junction coupling was observed in Ratl and human endothelial cells (Lampe et al., 1998). Conversely, in this study in the presence of DADS an increase in Cx43 phosphorylation at Ser262 and GJIC in rat primary VSMC was observed with a decrease in proliferation. These differences can be attributed to unique cellular systems and treatment times, and most importantly, the role of 


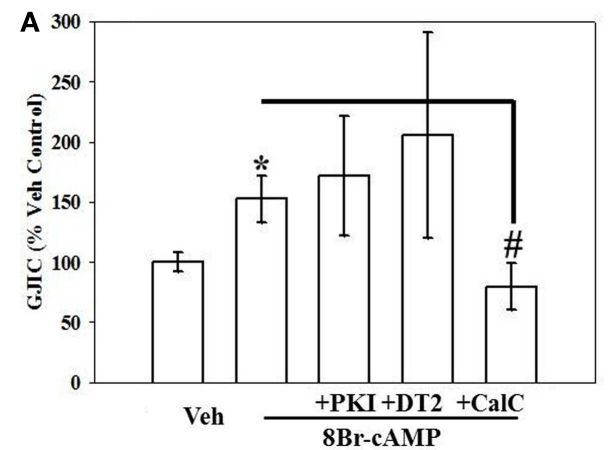

FIGURE 7 | Effect of kinase inhibition on (A) 8Br-cAMP- and (B) DADS-stimulated GJIC estimated by FRAP. Rat primary VSMCs were incubated for $15 \mathrm{~min}$ in the presence of the following PKA, PKG, and PKC inhibitors: PKI (10 $\mu \mathrm{M}), \mathrm{DT}-2(10 \mu \mathrm{M})$, and Calphostin-C (100 nM), respectively, followed by $8 \mathrm{Br}-\mathrm{CAMP}(100 \mu \mathrm{M})$ or DADS $(50 \mu \mathrm{M})$ alone for $15 \mathrm{~min}$. (A) Stimulation of GJIC by 8Br-cAMP was effectively inhibited by PKC inhibition alone but not by inhibition of PKA or PKG.

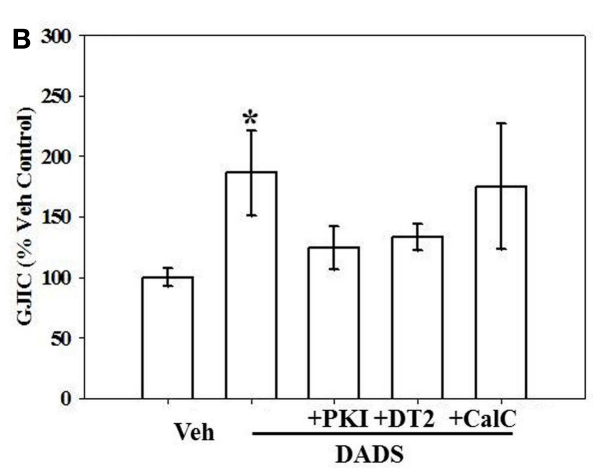

(B) DADS-mediated GJIC stimulation was partially (non-significantly) reversed by PKA or PKG inhibition. Data are mean \pm SE from an $n=4$ for the inhibitors treatment and an $n=6-9$ for control, 8Br-cAMP and DADS. Student-Newman-Keuls method for multiple comparisons following one-way ANOVA was used. ${ }^{*} p<0.05$ compared with normalized vehicle controls, ${ }^{*} p<0.05$ compared with cAMP-treated cells.

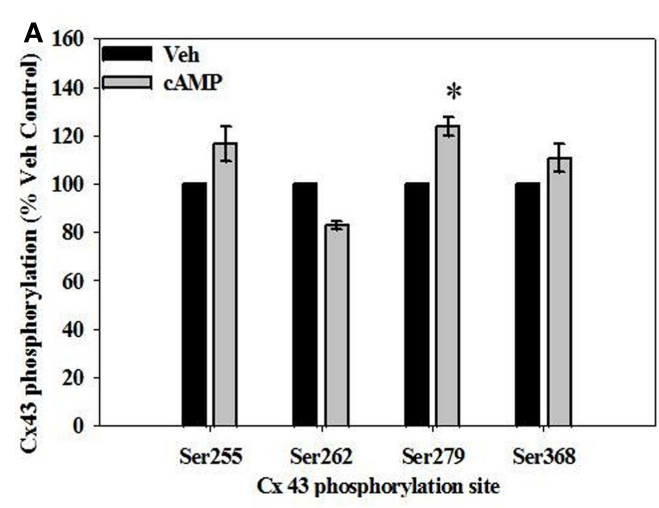

FIGURE 8 | In-cell Western analyses of site-specific Cx43 phosphorylation in rat primary VSMCs in the presence of (A) 8Br-cAMP and (B) DADS. (A) In the presence of 8Br-cAMP, phosphorylation of the MAPK-sensitive Ser279 was significantly increased compared to vehicle controls. (B) The presence of DADS significantly increased phosphorylation at the MAPK sensitive Ser255 and Ser279

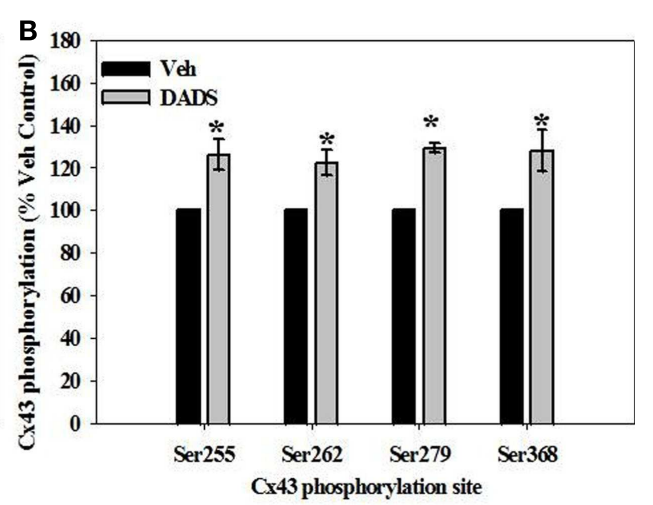

sites, p34 ${ }^{\text {cdc2 }}$ kinase-sensitive Ser262, and the PKC-sensitive Ser368. Data are mean \pm SE from three independent experiments with an $n=4$ for Ser279 phosphorylation, and $n=3-4$ for Ser255, 262, and 368 phosphorylation. Student-Newman-Keuls method for multiple comparisons following one-way ANOVA was used. * $p<0.05$ compared with respective vehicle controls.
Cx43 phosphorylation may be entirely cell-or tissue-specific that may also depend on the stages of cell growth.

Phosphorylation of Cx43 on Ser368 is mediated by PKC, and earlier reports using rat epithelial T51B cells strongly suggest that PKC directly phosphorylates Cx43 on Ser368 in vivo that contributes to a decrease in intercellular communication (Lampe et al., 2000) and that promotes carcinogenesis (Berthoud et al., 1992). These findings have served as the basis for the hypothesis that reduced cell-cell communication is a critical step in multistage carcinogenesis. The focus of the present study however was growth of normal VSMC and not modified or cancerous cells. Contrary to the earlier report (Lampe et al., 2000), in neonatal rat cardiomyocytes activation of PKC has been reported to cause an increase in junctional conductance (Kwak et al., 1995). The reason for these differences is not yet explained. In the present study
GJIC stimulated by $8 \mathrm{Br}$-cAMP was mediated by PKC, while that by DADS appeared to be mediated by PKG. Although 8Br-cAMP did not have any effects on the PKC-sensitive phosphorylation site Ser368 on Cx43, DADS significantly increased phosphorylation at this site with a decrease in VSMC growth, and possibly as shown earlier in the cardiomyocytes (Kwak et al., 1995; Kwak and Jongsma, 1996) the Cx43 in the cardiovascular system may behave differently than in other cell/tissue types.

It should be noted that the primary cells used in this study were derived from thoracic aorta. VSMCs of both resistance and conduit arteries express predominantly Cx43 and Cx45 (Little et al., 1995), and the expression of connexin proteins has been reported to vary particularly in arterioles and small arteries (Schmidt et al., 2008). In addition to this potential vascular heterogeneity among connexin isotypes, it is important to note that connexins in the intimal 
endothelium and adjacent medial wall are critical in the regulation of gross vessel function. Vasoconstrictor and vasodilatory signals travel rapidly along the vessel network due to the conduction of signals between endothelial and smooth muscle cells (Beny and Connat, 1992), and these occur through gap junctions. The spread of conducted dilations which travel large distances along the vessel are facilitated more by the endothelium, whereas conducted constrictions rely primarily on the smooth muscle. Even though the anatomical characteristics of endothelial cells may provide a more efficient pathway to coordinate vascular behavior (Haas and Duling, 1997), in this study the focus was on connexin physiology of medial wall-derived VSMCs.

It should also be noted that for many of the endpoints analyzed in this study, the overall changes generally ranged between 20 and $40 \%$ (with exceptions with the GJIC and inhibitor studies which demonstrated larger effects), and this may raise concerns over their physiological relevance. In comparison, the original characterization of DADS as an inducer of both $\mathrm{Cx} 43$ expression and functionality (Huard et al., 2004) reported increases in GJIC between 10 and 30\% after 8-h treatment with DADS and 50\% after $24 \mathrm{~h}$, agreeing closely with observations in the current study. Thus, in comparison with this original report using DADS as a stimulatory agonist, in the current study the observed changes are considered highly significant and physiologically relevant.

\section{REFERENCES}

Adderley, S. P., Joshi, C. N., Martin, D. N., and Tulis, D. A. (2012). Phosphodiesterases regulate BAY 41-2272-induced VASP phosphorylation in vascular smooth muscle cells. Front. Pharmacol. 3:10. doi:10.3389/fphar.2012.00010

Arunkumar, A., Vijayababu, M. R., Venkataraman, P., Senthilkumar, K., and Arunakaran, J. (2006). Chemoprevention of rat prostate carcinogenesis by diallyl disulfide, an organosulfur compound of garlic. Biol. Pharm. Bull. 29, 375-379.

Beny, J. L., and Connat, J. L. (1992). An electron-microscopic study of smooth muscle cell dye coupling in the pig coronary arteries. Role of gap junctions. Circ. Res. 70, 49-55.

Berthoud, V. M., Ledbetter, M. L. S., Hertzberg, E. L., and Saez, J. C. (1992). Connexin43 in MDCK cells: Regulation by a tumor-promoting phorbol ester and calcium. Eur. J. Cell Biol. 57, 40-50.

Bittman, K. S., and LoTurco, J. J. (1999). Differential regulation of connexin 26 and 43 in murine neocortical precursors. Cereb. Cortex 9, 188-195.

Blackburn, J. P., Peters, N. S., Yeh, H. I., Rothery, S., Green, C. R., and Severs, N. J. (1995). Upregulation of connexin43 gap junctions during early stages of human coronary atherosclerosis. Arterioscler. Thromb. Vasc. Biol. 15, 1219-1228.
Brisset, A. C., Isakson, B. E., and Kwak, B. R. (2009). Connexins in vascular physiology and pathology. Antioxid. Redox Signal. 11, 267-282.

Butt, E., Abel, K., Krieger, M., Palm, D., Hoppe, V., Hoppe, J., and Walter, U. (1994). cAMP and cGMPdependent protein kinase phosphorylation sites of the focal adhesion vasodilator-stimulated phosphoprotein (VASP) in vitro and in intact human platelets. J. Biol. Chem. 269, 14509-14517.

Chadjichristos, C. E., Morel, S., Derouette, J. P., Sutter, E., Roth, I., Brisset, A. C., Bochaton-Piallat, M. L., and Kwak, B. R. (2008). Targeting connexin 43 prevents platelet-derived growth factor-BB-induced phenotypic change in porcine coronary artery smooth muscle cells. Circ. Res. 102, 653-660.

Chen, H., Kovar, J., Sissons, S., Cox, K., Matter, W., Chadwell, F., Luan, P., Vlahos, C. J., SchutzGeschwender, A., and Olive, D. M. (2005). A cell-based immunocytochemical assay for monitoring kinase signaling pathways and drug efficacy. Anal. Biochem. 338, 136-142.

Cooper, C. D., Solan, J. L., Dolejsi, K. K., and Lampe, P. D. (2000). Analysis of connexin phosphorylation sites. Methods 20, 196-204.

Coutinho, P., Qiu, C., Frank, S., Tamber, K., and Becker, D. (2003). Dynamic

In summary, this study demonstrates a critical role of $\mathrm{Cx} 43$ in growth of primary VSM and supports a direct correlation between proliferation and $\mathrm{Cx} 43$ expression and gap junction communication. It is important to note that increased expression alone may not lead to increased gap junction communication, and that opening of the channels with functional conductance is the rate-limiting step in cell-cell communication. In this study Cx43-mediated GJIC was found to operate independently of site-specific $\mathrm{Cx} 43$ phosphorylation, demonstrating that the role of $\mathrm{Cx} 43$ phosphorylation may be mostly dependent on the type of cell/tissue. These findings may open new avenues for further understanding the factors that regulate VSMC growth.

\section{ACKNOWLEDGMENTS}

This study was supported by the ECU Undergraduate Research and Creative Activity Award (DNM), National Institutes of Health National Heart, Lung, and Blood Institute Grant R01HL081720 and NIH American Recovery and Reinvestment Act (2009) Grant R01-HL081720-03S2. We thank Jonathan Clay Fox for providing technical assistance cell culture and Shaquria P. Adderley, Ph.D., Brody School of Medicine, East Carolina University, Greenville, NC for valuable discussions related to this work.

changes in connexin expression correlate with key events in the wound healing process. Cell Biol. Int. 27, 525-541.

Dang, X., Jeyaraman, M., and Kardami, E. (2006). Regulation of connexin-43- mediated growth inhibition by a phosphorylatable aminoacid is independent of gap junctionforming ability. Mol. Cell. Biochem. 289, 201-207.

Dey, N. B., Foley, K. F., Lincoln, T. M., and Dostmann, W. R. (2005). Inhibition of cGMP dependent protein kinase reverses phenotypic modulation of vascular smooth muscle cells. J. Cardiovasc. Pharmacol. 45, 404-413.

Dostmann, W. R., Tegge, W., Frank, R., Nickl, C. K., Taylor, M. S., and Brayden, J. E. (2002). Exploring the mechanisms of vascular smooth muscle tone with highly specific, membrane-permeable inhibitors of cyclic GMP-dependent protein kinase I $\alpha$. Pharmacol. Ther. 93, 203-215.

Durante, W, Schini, V. B., Catovsky, S., Kroll, M. H., Vanhoutte, P. M., and Schafer, A. I. (1993). Plasmin potentiates induction of nitric oxide synthase in vascular smooth muscle cells. Am. J. Physiol. 264, H617H624.

Evans, W. H., and Martin, P. E. (2002). Gap junctions: structure and function. Mol. Membr. Biol. 19, 121-136.
Figueroa, X. F., and Duling, B. R. (2009). Gap junctions in the control of vascular function. Antioxid. Redox Signal. 11, 251-266.

Figueroa, X. F., Isakson, B. E., and Duling, B. R. (2006). Vascular gap junctions in hypertension. Hypertension 48, 804-811.

Giordano, A., Romano, S., Mallardo, M., D’Angelillo, A., Calí, G., Corcione, N., Ferraro P., and Romano, M. F. (2008). FK506 can activate transforming growth factor- $\beta$ signalling in vascular smooth muscle cells and promote proliferation. Cardiovasc. Res. 79, 519-526.

Goodwin, J. S., and Kenworthy, A. K. (2005). Photobleaching approaches to investigate diffusional mobility and trafficking of Ras in living cells. Methods 37, 154-164.

Haas, T. L., and Duling, B. R. (1997). Morphology favors an endothelial cell pathway for longitudinal conduction within arterioles. Microvasc. Res. 53, 113-120.

Haefliger, J. A., Nicod, P., and Meda. P. (2004). Contribution of connexins to the function of the vascular wall. Cardiovasc. Res. 62, 345-356.

Huard, C., Druesne, N., Guyonnet, D., Thomas, M., Pagniez, A., Le Bon, A. M., Martel, P., and Chaumontet, C. (2004). Diallyl disulfide (DADS) enhances gap-junctional intercellular communication by both direct and indirect mechanisms in rat liver cells. Carcinogenesis 25, 91-98. 
Indolfi, C., Di Lorenzo, E., Rapacciuolo, A., Stingone, A. M., Stabile, E., Leccia, A., Torella, D., Caputo, R., Ciardiello, F., Tortora, G., and Chiariello, M. (2000). 8-chlorocAMP inhibits smooth muscle cell proliferation in vitro and neointima formation induced by balloon injury in vivo. J. Am. Coll. Cardiol. 36, 288-293.

Isakson, B. E., Damon, D. N., Day, K. H., Liao, Y., and Duling, B. R. (2006). Connexin40 and connexin43 in mouse aortic endothelium: evidence for coordinated regulation. Am. J. Physiol. Heart Circ. Physiol. 290, H1199-H1205.

Jara, P. I., Boric, M. P., and Saez, J. C. (1995). Leukocytes express connexin 43 after activation with lipopolysaccharide and appear to form gap junctions with endothelial cells after ischemia-reperfusion. Proc. Natl. Acad. Sci. U.S.A. 92, 7011-7015.

Johnstone, S., Isakson, B., and Locke, D. (2009). Biological and biophysical properties of vascular connexin channels. Int. Rev. Cell Mol. Biol. 278, 69-118.

Joshi, C. N., Martin, D. N., Fox, J. C., Mendelev, N. N., Brown, T. A., and Tulis, D. A. (2011). The soluble guanylate cyclase stimulator BAY 412272 inhibits vascular smooth muscle growth through the PKA and PKG pathways. J. Pharmacol. Exp. Ther. 339, 394-402.

Kanemitsu, M. Y., Jiang, W., and Eckhart, W. (1998). Cdc2-mediated phosphorylation of the gap junction protein, connexin43, during mitosis. Cell Growth Differ. 9, 13-21.

Knowles, L. M., and Milner, J. A. (2000). Allyl sulfides modify cell growth. Drug Metabol. Drug. Interact. 17, 81-107.

Koo, S. K., Kim, D. Y., Park, S. D., Kang, K. W., and Joe, C. O. (1997). PKC phosphorylation disrupts gap junctional communication at $\mathrm{G} 0 / \mathrm{S}$ phase in clone 9 cells. Mol. Cell. Biochem. 167, 41-49.

Kumar, N. M., and Gilula, N. B. (1996). The gap junction communication channel. Cell 84, 381-388.

Kurjiaka, D. T., Steele, T. D., Olsen, M. V., and Burt, J. M. (1998). Gap junction permeability is diminished in proliferating vascular smooth muscle cells. Am. J. Physiol. 275, C1674C1682.

Kwak, B. R., and Jongsma, H. J. (1996). Regulation of cardiac gap junction channel permeability and conductance by several phosphorylating conditions. Mol. Cell. Biochem. 157, 93-99.
Kwak, B. R., Mulhaupt, F., Veillard, N., Gros, D. B., and Mach, F. (2002). Altered pattern of vascular connexin expression in atherosclerotic plaques. Arterioscler. Thromb. Vasc. Biol. 22, 225-230.

Kwak, B. R., Van Veen, T. A. B., Analbers, L. J. S., and Jongsma, H. J. (1995). TPA increases conductance but decreases permeability in neonatal rat cardiomyocyte gap junction channels. Exp. Cell Res. 220, 456-463.

Laird, D. W. (2005). Connexin phosphorylation as a regulatory event linked to gap junction internalization and degradation. Biochim. Biophys. Acta 1711, 172-182.

Laird, D. W., Puranam, K. L., and Revel, J. P. (1991). Turnover and phosphorylation dynamics of connexin43 gap junction protein in cultured cardiac myocytes. Biochem. J. 273, 67-72.

Lampe, P. D., Kurata, W. E., WarnCramer, B., and Lau, A. F. (1998). Formation of a distinct connexin 43 phosphoisoform in mitotic cells is dependent upon p34cdc2 kinase. $J$. Cell. Sci. 111, 833-841.

Lampe, P. D., and Lau, A. F. (2000). Regulation of gap junctions by phosphorylation of connexins. Arch. Biochem. Biophys. 384, 205-215.

Lampe, P. D., and Lau, A. F. (2004). The effects of connexin phosphorylation on gap junctional communication. Int. J. Biochem. Cell Biol. 36, 1171-1186.

Lampe, P. D., TenBroek, E. M., Burt, J. M., Kurata, W. E., Johnson, R. G., and Lau, A. F. (2000). Phosphorylation of connexin 43 on serine 368 by protein kinase $\mathrm{c}$ regulates gap junctional communication. J. Cell Biol. 149, 1503-1512.

Liao, Y., Regan, C. P., Manabe, I., Owens, G. K., Day, K. H., Damon, D. N., and Duling, B. R. (2007). Smooth muscle-targeted knockout of connexin43 enhances neointimal formation in response to vascular injury. Arterioscler. Thromb. Vasc. Biol. 27, 1037-1042.

Lincoln, T. M., Wu, X., Sellak, H., Dey, N., and Choi, C. S. (2006). Regulation of vascular smooth muscle cell phenotype by cyclic GMP and cyclic GMP-dependent protein kinase. Front. Biosci. 11, 356-367.

Little, T. L., Beyer, E. C., and Duling, B. R. (1995). Connexin 43 and connexin 40 gap junctional proteins are present in arteriolar smooth muscle and endothelium in vivo. Am. J. Physiol. 268, H729-H739.

Liu, X. M., Peyton, K. J., Mendelev, N. N., Wang, H., Tulis, D. A., and
Durante, W. (2009). YC-1 stimulates the expression of gaseous monoxide-generating enzymes in vascular smooth muscle cells. Mol. Pharmacol. 75, 208-217.

Maurice, D. H., and Haslam, R. J. (1990). Molecular basis of the synergistic inhibition of platelet function by nitrovasodilators and activators of adenylatecyclase: inhibition of cyclic AMP breakdown by cyclic GMP. Mol. Pharmacol. 37, 671-681.

Mendelev, N. N., Williams, V. S., and Tulis, D. A. (2009). Antigrowth properties of BAY 41-2272 in vascular smooth muscle cells. J. Cardiovasc. Pharmacol. 53, 121-131.

Muller-Borer, B. J., Cascio, W. E., Anderson, P. A. W., Snowwaert, J. N., Frye, J. R., Desai, N., Bagnell, C. R., Coleman, W. B., Grisham, J. W., and Malouf, N. N. (2004). Adult derived liver stem cells acquire a cardiac myocyte structural and functional phenotype in culture. Am. J. Pathol. 165, 135-145.

Nihei, O. K., Fonseca, P. C., Rubim, N. M., Bonavita, A. G., Lyra, J. S. Neves-dos-Santos, S., de Carvalho, A. C., Spray, D. C., Savino, W., and Alves, L. A. (2010). Modulatory effects of cAMP and PKC activation on gap junctional intercellular communication among thymic epithelial cells. BMC Cell Biol. 11, 3 . doi:10.1186/1471-2121-11-3

Norris, R. P., Freudzon, M., Mehlmann, L. M., Cowan, A. E., Simon, A. M., Paul, D. L., Lampe, P. D., and Jaffe, L. A. (2008). Luteinizing hormone causes MAP kinase dependent phosphorylation and closure of connexin 43 gap junctions in mouse ovarian follicles: one of two paths to meiotic resumption. Development 135, 3229-3238.

Paulson, A. F., Lampe, P. D., Meyer, R. A., Atkinson, M. A., Walseth, T. F., and Johnson, R. G. (2000) Cyclic AMP and LDL trigger a rapid enhancement in gap junction assembly through a stimulation of connexin trafficking. J. Cell. Sci. 113, 3037-3049.

Polacek, D., Bech, F., McKinsey, J. F., and Davies, P. F. (1997). Connexin43 gene expression in the rabbit arterial wall: effects of hypercholesterolemia, balloon injury and their combination. J. Vasc. Res. 34, 19-30.

Reinhard, M., Jarchau, T., and Walter, U. (2001). Actin-based motility: stop and go with Ena/VASP proteins. Trends Biochem. Sci. 26, 243-249.

Rivedal, E., and Opsahl, H. (2001). Role of PKC and MAP kinase in EGF- and
TPA-induced connexin43 phosphorylation and inhibition of gap junction intercellular communication in rat liver epithelial cells. Carcinogenesis 22, 1543-1550.

Ruch, R. J., Trosko, J. E., and Madhukar, B. V. (2001). Inhibition of connexin43 gap junctional intercellular communication by TPA requires ERK activation. J. Cell. Biochem. 83, 163-169.

Saitongdee, P., Becker, D. L., Milner, P., Knight, G. E., and Burnstock, G. (2004). Levels of gap junction proteins in coronary arterioles and aorta of hamsters exposed to the cold and during hibernation and arousal. J. Histochem. Cytochem. 52, 603-615.

Schaffer, E. M., Liu, J. Z., Green, J., Dangler, C. A., and Milner, J. A. (1996). Garlic and associated allyl sulfur compounds inhibit Nmethyl-N-nitrosourea induced rat mammary carcinogenesis. Cancer Lett. 102, 199-204.

Schlegel, N., and Waschke, J. (2009). VASP is involved in cAMP-mediated Rac 1 activation in microvascular endothelial cells. Am. J. Physiol. Cell Physiol. 296, C453-C462.

Schmidt, V. J., Wölfle, S. E., Boettcher, M., and de Wit C. (2008). Gap junctions synchronize vascular tone within the microcirculation. Pharmacol. Rep. 60, 68-74.

Shao, Q., Wang, H., McLachlan, E. Veitch, G. I., and Laird, D. W. (2005). Down-regulation of $\mathrm{Cx} 43$ by retroviral delivery of small interfering RNA promotes an aggressive breast cancer cell phenotype. Cancer Res. 65, 2705-2711.

Shen, J., Wang, L. H., Zheng, L. R., Zhu, J. H., and Hu, S. J. (2010). Lovastatin inhibits gap junctional communication in cultured aortic smooth muscle cells. J. Cardiovasc. Pharmacol. Ther. 15, 296-302.

Solan, J. L., Fry, M. D. TenBroek, E. M., and Lampe, P. D. (2003). Connexin43 phosphorylation at S368 is acute during $\mathrm{S}$ and $\mathrm{G} 2 / \mathrm{M}$ and in response to protein kinase $\mathrm{C}$ activation. J. Cell Sci. 116, 2203-2211.

Solan, J. L., and Lampe, P. D. (2007). Key connexin 43 phosphorylation events regulate the gap junction life cycle. J. Membr. Biol. 217, 35-41.

Touyz, R. M., and Schiffrin, E. L. (1997). Growth factors mediate intracellular signaling in vascular smooth muscle cells through protein kinase Clinked pathways. Hypertension 30, 1440-1447.

Trosko, J. E., and Ruch, R. J. (1998). Cell-cell communication in carcinogenesis. Front. Biosci. 15, D208D236. 
Wade, M. H., Trosko, J. E., and Schindler, M. (1986). A fluorescence photobleaching assay of gap junction-mediated communication between human cells. Science 232, 525-528.

Wu, Y., Bond, M., Sala-Newby, G., and Newby, A. (2006). Altered Sphase kinase-associated protein-2 levels are a major mediator of cyclic nucleotide-induced inhibition of vascular smooth muscle cell proliferation. Circ. Res. 98, 1141-1150.

Xie, H., Laird, D. W., Chang, T. -H., and Hu, V. W. (1997). A mitosis-specific phosphorylation of the gap junction protein connexin 43 in human vascular cells: Biochemical characterization and localization. J. Cell Biol. 137, 203-210.

Yamasaki, H., Krutovskikh, V., Mesnil, M., and Omori., and Y. (1996). Connexin genes and cell growth control. Arch. Toxicol. 18, 105-114.
Yamasaki, H., and Naus, C. C. G. (1996). Role of connexin genes in growth control. Carcinogenesis 17, 1199-1213.

Yao, J., Hiramatsu, N., Zhu, Y., Morioka, T., Takeda, M., Oite, T., and Kitamura, M. (2005). Nitric oxidemediated regulation of connexin 43 expression and gap junctional intercellular communication in mesangial cells. J. Am. Soc. Nephrol. 16, 58-67.

Yeh, H. I., Lupu, F., Dupont, E., and Severs, N. J. (1997). Upregulation of connexin43 gap junctions between smooth muscle cells after balloon catheter injury in the rat carotid artery. Arterioscler. Thromb. Vasc. Biol. 17, 3174-3184.

Yun, S. P., Ryu, J. M., Park, J. H., Kim, M. O., Lee, J. H., and Han, H. J. (2012). Prostaglandin E2 maintains mouse ESC undifferentiated state through regulation of connexin $31,-43$ and -45 expression: Involvement of glycogen synthase kinase $3 \beta / \beta$-catenin. Biol. Cell. doi:10.1111/boc.201100032. [Epub ahead of print].

Zhang, W., DeMattia, J. A., Song, H., and Couldwell, W. T. (2003). Communication between malignant glioma cells and vascular endothelial cells through gap junctions. J. Neurosurg. 98, 846-853.

Zhang, Y. W., Wen, J., Xiao, J. B., Talbot, S. G., Li, G. C., and Xu, M. (2006). Induction of apoptosis and transient increase of phosphorylated MAPKs by diallyl disulfide treatment in human nasopharyngeal carcinoma CNE2 cells. Arch. Pharm. Res. 29, 1125-1131.

Conflict of Interest Statement: The authors declare that the research was conducted in the absence of any commercial or financial relationships that could be construed as a potential conflict of interest.

Received: 04 April 2012; accepted: 01 June 2012; published online: 21 June 2012.

Citation: Joshi CN, Martin DN, Shaver $P$, Madamanchi C, Muller-Borer BJ and Tulis DA (2012) Control of vascular smooth muscle cell growth by connexin 43. Front. Physio. 3:220. doi: 10.3389/fphys.2012.00220

This article was submitted to Frontiers in Vascular Physiology, a specialty of Frontiers in Physiology.

Copyright $\odot 2012$ Joshi, Martin, Shaver, Madamanchi, Muller-Borer and Tulis.

This is an open-access article distributed under the terms of the Creative Commons Attribution Non Commercial License, which permits non-commercial use, distribution, and reproduction in other forums, provided the original authors and source are credited. 